\title{
What type of delirium would you like: Hyperactive, hypoactive, or mixed? None, thanks
}

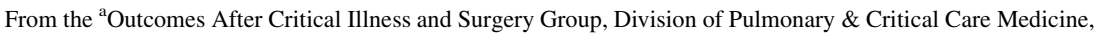 \\ Johns Hopkins University School of Medicine, Baltimore, Md; ${ }^{\mathrm{b}}$ Max Rady College of Medicine, University of \\ Manitoba; and ${ }^{\mathrm{c} C a r d i a c}$ Sciences Program, St Boniface Hospital, Winnipeg, Manitoba, Canada. \\ Disclosures: Arora has an unrestricted educational grant from Pfizer Canada Inc, and has received honoraria from \\ Mallinckrodt Pharmaceuticals. All other authors have nothing to disclose with regard to commercial support. \\ Received for publication Aug 31, 2017; accepted for publication Sept 2, 2017; available ahead of print Oct 4, \\ 2017. \\ Address for reprints: Rakesh C. Arora, MD, PhD, FRCSC, Cardiac Sciences Program, St Boniface Hospital, \\ CR3015-369 Tache Ave, Winnipeg, Manitoba, Canada R2H 2A6 (E-mail: rakeshcarora@gmail.com). \\ J Thorac Cardiovasc Surg 2018;155:240-1 \\ $0022-5223 / \$ 36.00$ \\ Copyright $(\odot 2017$ by The American Association for Thoracic Surgery \\ http://dx.doi.org/10.1016/j.jtcvs.2017.09.005
}

Carrie M. Goodson, MD, MHS, ${ }^{\mathrm{a}}$ Yui Chang, BSc, ${ }^{\mathrm{b}}$ and Rakesh C. Arora, MD, PhD, FRCSC ${ }^{\mathrm{b}, \mathrm{c}}$

Delirium is a syndrome of acute and fluctuating mental status, inattention, and altered level of consciousness. Up to $52 \%$ of postoperative cardiac surgery patients experience delirium, which has been associated with increased mortality and cognitive dysfunction. ${ }^{1}$ This high prevalence is likely due to the vulnerable nature of the cardiac surgery population at baseline, with additional cardiac and noncardiac stressors from surgery. ${ }^{2}$ The pathophysiology of delirium is complex, involving neurotransmitter dysfunction and dysregulation secondary to systemic disturbances (eg, surgery and infection), ${ }^{3}$ which is likely related to the clinical manifestation of delirium as 1 of 3 motor subtypes: hypoactive (56\%$68 \%)$, hyperactive $(1 \%-10 \%)$, and mixed $(21 \%-31 \%)$.

Lee and colleagues ${ }^{6}$ evaluate the trajectory of patients with postoperative delirium, comparing different motor subtypes. The authors reasonably hypothesized that hypoactive delirium is associated with worse outcomes than hyperactive or mixed delirium. Their rationale is that the hypoactive subtype is often underrecognized, resulting in a delay in addressing the cause of delirium. The authors diagnosed postoperative delirium in $13.8 \%$ of 600 patients, of which $28.9 \%$ were hyperactive and $31.3 \%$ were hypoactive, according to routine bedside nursing assessments using the Confusion Assessment Method for the Intensive Care Unit (CAM-ICU) and Richmond Agitation and Sedation Scale (RASS). Recruitment (88\% of screened patients) and retention $(100 \%)$ was exemplary. This overall prevalence is relatively low despite nearly ubiquitous use of sedation $(92 \%-100 \%)$. The proportion of hyperactive delirium is almost 3 times greater than previous reports., ${ }^{4,5-10}$ Taken together, this suggests that delirium, particularly hypoactive delirium, was inadequately detected.

The primary outcome of fast-track failure (composite of intensive care unit length of stay $>48$ hours, intensive care unit readmission, and 30-day mortality) was associated with delirium of any subtype (relative risk, 2.48; 95\% confidence interval, 1.29-4.79) when adjusted for confounders

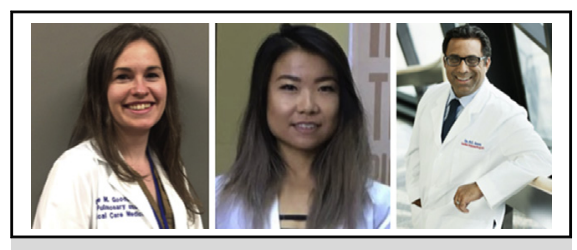

Carrie M. Goodson, MD, MHS, Yui Chang, BSc, and Rakesh C. Arora, MD, PhD, FRCSC

Central Message

This study finds delirium, but not motor subtype, influences fast-track failure after cardiac surgery; insensitive detection of hypoactive delirium may limit the findings.

See Article page 268.

in the total effect analysis with no difference between motor subtypes. This outcome, contrary to the original hypothesis, may be partially attributed to the poor outcomes of the mixed delirium group, members of which were significantly sicker at baseline and experienced worse delirium. Most of the effect of delirium on fast-track failure was indirect, mediated largely by increased duration of mechanical ventilation.

Motor subtype is one phenotypic characteristic of delirium, severity is another. The authors quantified severity as delirium duration and score on the Richmond Agitation and Sedation Scale and found it was associated with longer duration of mechanical ventilation. Although typically reserved for nonintensive care unit settings, ${ }^{11,12}$ delirium severity is an important measurement that can now be done with the Confusion Assessment Method for the Intensive Care Unit-7 (CAM-7), ${ }^{13}$ which future work in this field should consider using. No matter the phenotype, longer duration of delirium is strongly associated with increased mortality, mechanical ventilation time, and intensive care unit length of stay, as well as a slower cognitive recovery. ${ }^{10,14}$

This study underscores that delirium of any motor subtype is associated with worse postoperative outcomes. Accurately detecting and treating delirium is important for short- and long-term functional outcomes, particularly in vulnerable older adults, who make up much of the contemporary cardiac surgical population. Although these data do not find patients with hypoactive versus mixed/hyperactive delirium have more fast-track failure, future studies should consider more sensitive tools for 
delirium presence and severity detection before drawing this conclusion.

\section{References}

1. Brown CH. Delirium in the cardiac surgical ICU. Curr Opin Anaesthesiol. 2014; 27:117-22.

2. Arora RC, Djaiani G, Rudolph JL. Detection, prevention, and management of delirium in the critically ill cardiac patient and patients who undergo cardiac procedures. Can J Cardiol. 2017;33:80-7.

3. Maldonado JR. Acute brain failure: pathophysiology, diagnosis, management, and sequelae of delirium. Crit Care Clin. 2017;33:461-519.

4. Robinson TN, Raeburn CD, Tran ZV, Brenner LA, Moss M. Motor subtypes of postoperative delirium in older adults. Arch Surg. 2011;146:295-300.

5. Albrecht JS, Marcantonio ER, Roffey DM, Roffey DM, Orwig D, Magaziner J, et al. Stability of postoperative delirium psychomotor subtypes in individuals with hip fracture. J Am Geriatr Soc. 2015;63:970-6.

6. Lee A, Mu JL, Chiu CH, Gin T, Underwood MJ, Joynt GM. Effect of motor subtypes of delirium in the intensive care unit on fast-track failure after cardiac surgery. J Thorac Cardiovasc Surg. 2018;155:268-75.e1.

7. Stransky M, Schmidt C, Gansimeier P, Grossman E, Haneya A, Moritz S, et al. Hypoactive delirium after cardiac surgery as an independent risk factor for prolonged mechanical ventilation. J Cardiothorac Vasc Anesth. 2011;25: 968-74.

8. Breu A, Stransky M, Metterlein T, Werner T, Trabold B. Subsyndromal delirium after cardiac surgery. Scand Cardiovasc J. 2015;49:207-12.

9. McPherson JA, Wagner CE, Boehm LM, Hall JD, Johnson DC, Miller LR, et al. Delirium in the cardiovascular ICU: exploring modifiable risk factors. Crit Care Med. 2013;41:405-13.

10. Saczynski JS, Marcantonio ER, Quach L, Fong TG, Gross A, Inouye SK, et al Cognitive trajectories after postoperative delirium. N Engl J Med. 2012;367: $30-9$.

11. Breitbart W, Rosenfeld B, Roth A, Smith MJ, Cohen K, Passik S. The Memorial Delirium Assessment Scale. J. Pain Symptom Manage. 1997;13:128-37.

12. Trzepacz PT, Mittal D, Torres R, Kanary K, Norton J, Jimerson N. Validation of the Delirium Rating Scale-revised-98: comparison with the delirium rating scale and the cognitive test for delirium. J Neuropsychiatry Clin Neurosci. 2001;13: 229-42.

13. Khan BA, Perkins AJ, Gao S, Hui S, Campbell NL, Farver MO, et al. The confusion assessment method for the ICU-7 Delirium Severity Scale: a novel delirium severity instrument for use in the ICU. Crit. Care Med. 2017;45:851-7.

14. Shehabi Y, Riker RR, Bokesch PM, Wisemandle W, Shintani A, Ely EW, et al. Delirium duration and mortality in lightly sedated, mechanically ventilated intensive care patients. Crit Care Med. 2010;38:2311-8. 